\title{
Muito além da alcova: a participação da mulher viúva na economia do Antigo Regime (Rio de Janeiro, c. 1763-1808)
}

\author{
Beyond the alcove: widows participation in the economy of the Ancient \\ Regime (Rio de Janeiro, c. 1763-1808)
}

\section{Cristiane Fernandes Lopes Veiga}

Universidade de São Paulo

\section{Resumo}

O objetivo deste artigo é estudar a participação da mulher viúva na economia e sociedade da capitania do Rio de Janeiro durante os 45 anos que antecederam a chegada da família real ao Brasil. Para tanto nos dedicamos à análise dos inventários post-mortem e testamentos disponíveis no Arquivo Nacional do Rio de Janeiro nos Fundos Juízo de Órfãos e no Arquivo Ultramarino, especialmente os casos em que havia a necessidade de tutores para os órfãos menores de idade. Por essa documentação observamos que muitas viúvas foram encarregadas de gerir grandes patrimônios depois de feitas as partilhas. Elas se tornaram responsáveis pela manutenção tanto de si quanto dos órfãos até sua maioridade, casamento ou emancipação.

Palavras-chave: Viúvas; Tutoria; Rio de Janeiro.

\begin{abstract}
The main purpose of this study is to explore the widows' participation in Rio de Janeiro captaincy's economyand societyduring thelastforty-fiveyears before the Portuguese Royal Familyarrival in Brazil. Therefore, we have dedicated to analyze postmortem inventories and wills available in National Archive of Rio de Janeiro, in the collections "Juízo de Órfãos e Ausentes", "Juízo de For a" and "Casa de Suplicação", as well as the documents available on the Overseas Historical Archive, especially cases which there was a need for underage orphans' tutors. From this documentation we have found that many widows were in charge of managing large heritages after the shares were made. They became responsible for the maintenance of both themselves and orphans until their adulthood, marriage or emancipation.
\end{abstract}

Keywords: Widows; Cuardianship; Rio de Janeiro. 


\section{Dossiê
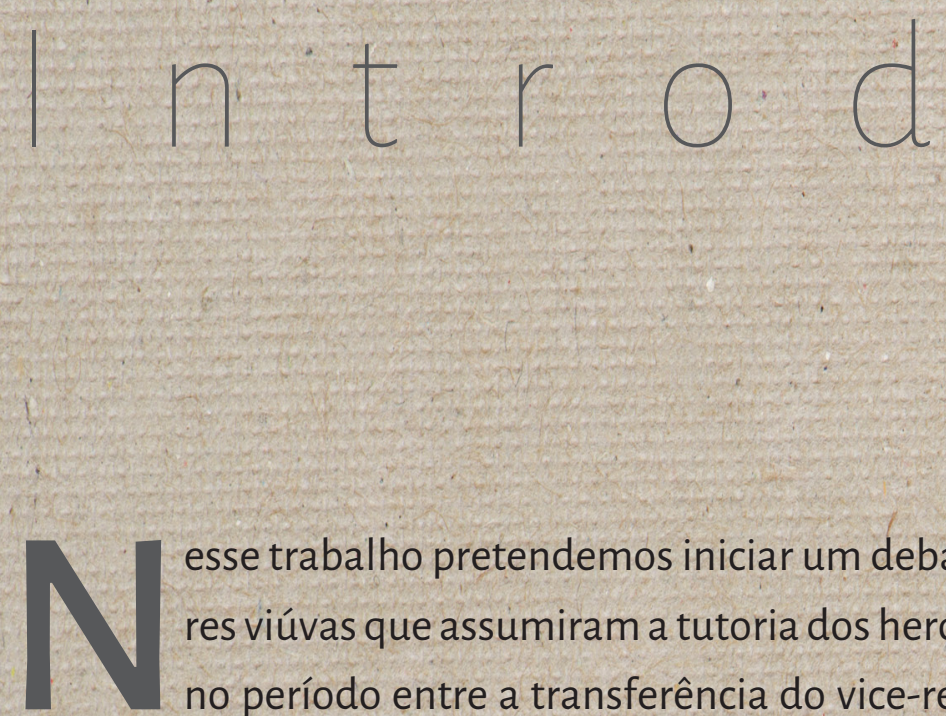

U
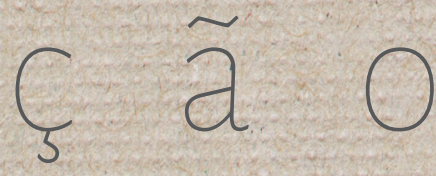

até a chegada ao Brasil da família real. Para tanto, estudamos os inventários post-mortem à disposição no Arquivo Nacional, sobretudo a documentação do Juízo de Órfãos e Ausentes, Juízo de Fora e Casa de Suplicação, bem como as requisições de viúvas endereçadas ao ConseIho Ultramarino. O que propomos aqui é examinarmos qual o papel da mulher na sociedade e economia coloniais, procurando entender como os tradicionais papéis de gênero foram sendo moldados e adaptados pelas necessidades cotidianas dessas viúvas, conferindo a essas mulheres poderes que elas procuravam manter apesar dos limites que Ihes eram impostos pelo meio em que viviam.

O Antigo Regime se caracterizava pela familiaridade de sua população com a morte, a fome, as guerras, a elevada taxa de mortalidade infantil e neonatal, as epidemias, as pestes e as doenças endêmicas (PELLEGRIN \& WINN, 1998, p. 15). Conviver com o fim da vida cotidianamente só vai ser um fato estranho ao indivíduo a partir de meados século XIX (LIVI-BACCI, 1997, p. 118-20). Na colônia portuguesa do Atlântico a situação muitas vezes se agravava pela falta de assistência local e pela distância dos núcleos de povoamento.

Uma série de mudanças estava em curso na América lusa durante o desenrolar do século XVIII. O ouro das Minas Gerais levou a coroa portuguesa a dedicar mais atenção à sua colônia, ao mesmo tempo em que o comércio do Oriente perdia vigor. Uma onda de migrantes da metrópole chegou ao Brasil à procura de riqueza ajudando a ocupar e construir o que seria o território brasileiro. A cana-de-açúcar e os engenhos ganhavam destaque nas capitanias ao sul da então capital do vice-reino, na cidade de Salvador. Uma economia de subsistência, baseada em produtos para o consumo, expandia-se e preenchia vazios deixados pela necessidade de gêneros como farinha, frutas, carne, feijão e milho. Nesse contexto, marcado por conflitos e disputas, viviam as mulheres viúvas: 
De acordo com as Ordenações Filipinas, as mulheres eram consideradas meeiras do patrimônio do casal e com a extinção do matrimônio por falecimento de um dos cônjuges, as viúvas se tornavam cabeça de casal e herdeiras de metade de tudo o que o casal construiu na constância do matrimônio (ORDENAÇÕES, 1870, p. 832). A tutela dos filhos também podia ser requerida' por elas (ORDENAÇÕES, 1870, p. 994) ou instituída em favor da esposa pelo marido em testamento'.

As viúvas nomeadas para serem tutoras de seus filhos, além da meação que Ihes cabia quando o marido morria, segundo o que previa o matrimônio por carta de ametade ${ }^{2}$, ainda administravam as legítimas de seus filhos menores quando havia bens, o que muitas vezes colocava sob sua responsabilidade patrimônios inteiros dos casais. Sabemos que não era raro que familiares, sobretudo homens, ajudassem as viúvas a manter os legados, nos casos por nós estudados neste trabalho, no entanto, privilegiamos os inventários cujas viúvas e mães fossem administradoras e tutoras dos patrimônios e dos herdeiros até a entrega da herança ao órfão.

Com base nessas considerações observamos que havia uma sobreposição de papéis nos casos em que as mães eram tutoras, pois além de mães, elas eram provedoras de seus filhos. As viúvas, que também eram mães tutoras, ultrapassavam as barreiras dos tradicionais papéis de gênero de mães e esposas ${ }^{3}$, tornavam-se senhoras de escravos e de terras, negociantes ou lavradoras. As leis do Reino garantiam a elas essa possibilidade o que ainda Ihes assegurava, frequentemente, uma fluidez nos limites entre os espaços públicos e domésticos no seu cotidiano.

1 É importante salientar que tanto os inventários quanto a documentação disponível do Conselho Ultramarino são fontes produzidas pelos representantes da coroa na América Portuguesa e na metrópole, com base em uma legislação que teve sua origem em um complexo jogo de negociações, de concessões e de idas e vindas que cooptavam tanto o monarca quanto seus representantes e seus vassalos. Dessa forma, para compreendermos a documentação e a legislação que as normatizava faz-se necessário entendermos como essas negociações aconteceram no âmbito do poder central e periférico. Para Silvia H. Lara (2000), 'é preciso se analisar o 'modo de produção' das leis e das normas jurídicas da sociedade para se entender a legislação de um período. A vontade do soberano, expressa na lei, era resultado de um importante jogo política entre as diversas instâncias do governo real". Os inventários post-mortem e a documentação do Conselho Ultramarino, portanto, devem obedecer a padrões e normas estabelecidos para que sejam válidos e aceitos, ou seja, necessitam se.conformar ao conjunto da legislação que os rege. Dessa forma, os documentos por nós estudados entre 1763 e 1808 são tanto testemunhas do pensamento e das atitudes dos agentes de dominação coevos, quanto daqueles que o produziam na colônia. E ainda, são o resultado de constantes adaptações das necessidades que se colocavam no dia a dia dos súditos da coroa.

2 Também conhecido como casamento segundo as Leis do Reino, o casamento por carta de ametade era aquele em que, depois do falecimento do marido, os bens do casal eram divididos entre a esposa e os herdeiros. Nessa modalidade de matrimônio, 0 dote da esposa, quando houvesse, deveria retornar intacto para ela (ORDENAÇÕES, 1870, p. 832).

3 A preocupação de pesquisadores em delimitar conceitualmente as relações de gênero, determinadas em termos das relações de poder entre homens e mulheres, ganhou destaque com a necessidade das acadêmicas feministas em estruturar seu objeto de estudos, as mulheres, a partir da década de 1960. A produção de trabalhos sob a perspectiva de gênero tem demonstrado que há a necessidade, sobretudo, de se historicizar questões relativas aos papéis de homens e mulheres. Para tanto, é preciso se ter em mente que esses papéis são construídos com base em estruturas de poder e em culturas específicas. As pesquisas feitas nos últimos anos, com base nos pressupostos de gênero, realçam o fato de que deve-se levar em conta, ainda, que as relações de gênero se concretizam de forma diversa de acordo com o pertencimento das mulheres a classes e raças diferentes. Sob essa perspectiva se moldam os papéis de homens e mulheres, bem como conformam-se e diferenciam-se as esferas do público e do privado, tradicionalmente associados ao masculino e ao feminino. Para uma discussão a respeito de questões relativas aos estudos de gênero, ver Scott (1990), Piscitelli (2002) e Franco (2015). 


\section{Além dos muros}

A transferência do vice-reinado da Bahia para o Rio de Janeiro veio consolidar uma situação previsível por volta de 1750. Desde então, a cidade do Rio de Janeirojá surgia como importante porto de importação e exportação do Império, constituindo-se como destacada praça mercantil da região Centro-Sul. Aliava-se a tal fato a necessidade de se empreender uma fiscalização mais efetiva do ouro das Minas. Os constantes conflitos nas capitanias do Sul (Rio Grande de São Pedro e Santa Catarina) e na Colônia do Sacramento exigiam maior proximidade das autoridades coloniais dessas áreas ameaçadas. Nessa mesma época, a maioria do aparelho administrativo já se achava instalado na cidade de São Sebastião do Rio de Janeiro4.

Durante o século XVII, a capitania do Rio de Janeiro vinha ganhando proeminência no cenário do Império ultramarino português. Observa-se a multiplicação do número de engenhos que, em 1580, eram apenas três, passam a 40 em 1612, chegando a 60 fábricas em 1629 e, em 1639 , somavam 110 (SAMPAIO, 2003, p. 65) ${ }^{5}$. Juntamente com a expansão açucareira, cresceu a presença de mercadores fluminenses no tráfico atlântico de cativos, o que demonstra a dinâmica dessa praça frente as demais da colônia (FLORENTINO, 1995). Ao mesmo tempo, a reconquista de Angola, com a forte presença da elite mercantil e política da capitania no processo ${ }^{6}$, comprovava a dinamização da economia fluminense (SAMPAIO, 2003).

Os primeiros engenhos surgiram nas proximidades da área do povoamento inicial da cidade de São Sebastião. Com o tempo, eles foram se afastando, seguindo rumo ao interior, acompanhando a expansão agrícola e o consequente aumento da população (ABREU, 2010, p. 83). Durante o período entre a segunda metade do século XVII e o seguinte, houve o crescimento do setor da produção de alimentos (SAMPAIO, 2003, p. 115 e seguintes). Enquanto isso, as fábricas foram ganhando o espaço do recôncavo da Guanabara, até a Baixada Fluminense (SCHAEFFER \& GEICER, 1952) e a capitania de Paraíba do Sul (LAMECO, 2007). Entretanto ao mesmo tempo, o mercado internacional sofria com as constantes oscilações no preço do açúcar e com as crises políticas e econômicas durante todo o período, cujas consequências sentia-se abater sobre a colônia.

Durante o século XVII uma série de disputas entre nações contribuíram para uma nova conformação de forças no mundo e na colônia lusa. O conflito entre Espanha e Províncias Unidas

4 Nessa época, já estavam instalados na cidade do Rio de Janeiro o Tribunal da Relação (1751), a Mesa de Inspeção (1751) e a Intendência do Ouro (1751) (ALDEN, 1968, p. 45).

5 Abreu (2010, p. 81) contabiliza, em 1580, três engenhos, e 131 entre 1691-1700.

60 próprio governador da capitania, Salvador Correa de Sá e Benevides, lutou para recuperar Angola dos holandeses. 
resultou na ocupação holandesa em Pernambuco e na Bahia (1630-1654) durante a união das coroas de Portugal e Espanha. Com a Restauração portuguesa, houve o aumento dos custos militares com os embates que se estenderam na Península Ibérica até 1668 e um sério déficit com a interrupção do comércio com as províncias espanholas. A tomada de Luanda pelos batavos dificultou a obtenção de mão de obra escrava. Por fim, a entrada das Antilhas no mercado do açúcar (1650) resultou na perda de mercado consumidor, na baixa dos preços e no aumento da competição para obter mão de obra escrava.

Ao mesmo tempo, internamente, o crescimento da atividade mineradora teve consequências diversas. Durante a primeira metade do XVIII, o resultado foram crises de abastecimento e fome na capitania (SILVA, 1990), que logo deram início ao incremento do setor de alimentos para abastecer as minas. Em seguida, os conflitos entre paulistas e portugueses, com a vitória dos Emboabas sobre os paulistas, resultou na inserção de fluminenses no mercado das minas, colocando-os definitivamente como protagonistas do complexo atlântico português. Por fim, a construção do Caminho Novo reforçava a participação da capitania fluminense no comércio interno e externo (SAMPAIO, 2003, p. 80-99).

Na segunda metade do século XVIII, aconteceu uma mudança política decisiva: a ascensão ao poder do Marquês de Pombal (FALCON, 1982). No setor econômico, os produtos coloniais sofriam com crises sazonais, provocando déficits elevados na balança comercial portuguesa. 0 volume de ouro extraído das minas diminui entre as décadas de 1760 e 1780 . O açúcar sofria com baixas nos preços (1749-1776), os diamantes escasseavam e aumentava o valor dos escravos (ARRUDA, 1980). Diante de tal conjuntura, Sebastião José de Carvalho e Melo, como ministro de $D$. José, iniciou uma série de medidas para recuperar a economia portuguesa e aumentar a fiscalização sobre as possessões portuguesas no Atlântico?.

Na colônia, o Marquês do Lavradio assumiu o vice-reinado. Simpatizante do movimento ilustrado, ele empreendeu uma série de medidas para diversificar a economia e desenvolver a agricultura, melhorar as defesas da colônia, bem como dinamizar a administração ${ }^{8}$. Os governos dos vice-reis posteriores ao do Marquês do Lavradio começaram com uma conjuntura econômica mais favorável, com tendência de alta nos preços do açúcar, apesar de ainda haver uma preocupação dos governantes da metrópole, sobretudo com D. Rodrigo de Souza Coutinho,

7 Entre elas podemos destacar a instalação da Mesa de Inspeção (1751), Tribunal da Relação do Rio de Janeiro (1751), criação das Companhias de Comércio do Grão-Pará e Maranhão (1755) e Pernambuco e Paraíba (1759), instalação do Colégio dos Nobres (1760), organização da Intendência Geral de Polícia do Rio de Janeiro (1766), criação de aulas régias, expulsão dos Jesuítas (1759), reforma da Universidade de Coimbra (1772).

8 Pelo relatório que o Marquês do Lavradio (1842) escreveu para entregar a seu sucessor, percebe-se a preocupação em se implantar novas culturas que aumentassem a arrecadação e diversificassem a economia, são elas: o cultivo da cochonilha, do cânhamo, do anil, do algodão, do fumo da Virginia e do arroz Carolina. 
em promover o desenvolvimento dos diversos setores agrícolas nos territórios de ultramar (DIAS, 1968, p. 112-3; MAXWELL, 1973).

No final do século XVIII, o porto do Rio de Janeiro era o primeiro em importação e exportação de produtos e se destacava na redistribuição de mercadorias para outras capitanias. A sede do vice-reinado participava com $38,1 \%$ das importações e $34,2 \%$ das exportações, à frente da Bahia, cujos índices correspondem a $27,1 \%$ e $26,4 \%$ no mesmo período. Pernambuco ficava em terceiro lugar de participação absoluta ( $21 \%$ e $22,7 \%$, respectivamente), seguido por Maranhão e Pará; em últimos lugares, Santos, Paraíba e Ceará (ARRUDA, 1980, p. 133). O início da década de 1790 foi um momento de crescimento da economia açucareira devido aos preços elevados, consequência da interrupção no fornecimento do produto pelo Haiti. Entretanto, entre 1799 e 1811, o preço do açúcar branco exportado pelo porto do Rio de Janeiro caiu a uma taxa anual de $5,7 \%$, e suas receitas a uma taxa anual de $19,9 \%$ (FRACOSO, 1992, p. 22). Alden (1984, p. 356) assinala que, entre 1769 e 1778 , houve um crescimento de $235 \%$ na produção açucareira, quando o número de engenhos passou de 56 para 104, elevando-se também o número de escravos de 3.192 para 4.871.

\section{Pela muita capacidade que ela tem...}

É nesse contexto que pretendemos analisar as tutelas dos herdeiros menores assumidas pelas viúvas nos inventários post-mortem. O Juiz de Órfãos era a autoridade responsável pelos inventários que envolvessem algum herdeiro órfão menor de vinte e cinco anos, fossem filhos, netos ou qualquer outro menor indicado como herdeiro do inventariado. Para cuidar dos interesses desses órfãos era nomeado um tutor, indicado em testamento ou sugerido pelo Escrivão dos Órfãos que deveria ser aprovado pelo Juiz de Órfãos. Os tutores podiam ser as mães, avós, parentes próximos ou pessoa idônea, de qualidade 9 e com bens. Cabia ao tutor administrar com zelo os bens das crianças e era obrigado a prestar contas do que fazia com a herança quando solicitado.

Ainda havia o curador geral dos Órfãos, cuja função era fiscalizar a partilha e as contas apresentadas pela inventariante, bem como a boa administração do legado. Em caso de má gestão, a legislação previa que o tutor fosse responsabilizado e mandava que se restituísse o prejuízo à

90 conceito de qualidade, geralmente, está ligado à cor. Relaciona-se à ideia de que alguém tem qualidade, também, quando não se sujeita a trabalhos mecânicos. Sobre o conceito de qualidade ligada à cor, ver Paiva (2016, p. 57-81). Sobre a ideia de calidad na América Espanhola, consultar McCAA (1984, p. 477-501). Sobre a discussão do conceito de qualidade e cor nas Américas portuguesa e hispânica, ver Raminelli (2015, p. 207-239). 
legítima do menor. Qualquer ameaça aos bens dos herdeiros sob encargo do tutor ou o abandono do inventário pela viúva inventariante permitia o sequestro dos bens.

A tutela dos menores podia ser testamentária, legítima ou dativa. Tanto mães quanto avós, dizia o Título 102, no Livro 4 das Ordenações, podiam ser tutoras desde que não se casassem novamente e renunciassem à Lei de Velleano ${ }^{10}$. Nos casos em que as mães não foram indicadas em testamento (tutoras testamentárias) ou não requisitavam a tutoria dos filhos, o código filipino previa que pessoas próximas aos menores fossem escolhidas, tais como familiares (tutores legítimos $)^{11}$. Se nenhuma destas condições pudesse ser cumprida, fazia-se a nomeação de uma pessoa idônea, de qualidade e com bens para a tutela (tutoria dativa) (SILVA, 1789, p. 818) ${ }^{12}$.

Na documentação consultada, entre os 113 tutores indicados para cuidar dos interesses dos filhos menores de inventariados, encontramos os seguintes números: em 37 casos as mães eram tutoras, em 19 não foi informado o parentesco, 13 eram tios, nove avôs, oito irmãos, oito cunhados, sete padrastos, quatro testamenteiros, em três não foi possível identificar o tutor, dois parentes, dois menores se emanciparam e não precisaram de tutor, um padrinho e um pelas condições dos autos não pudemos obter a informação, sendo classificado como incompleto (Gráfico 1).

Nos casos em que as mães eram tutoras,

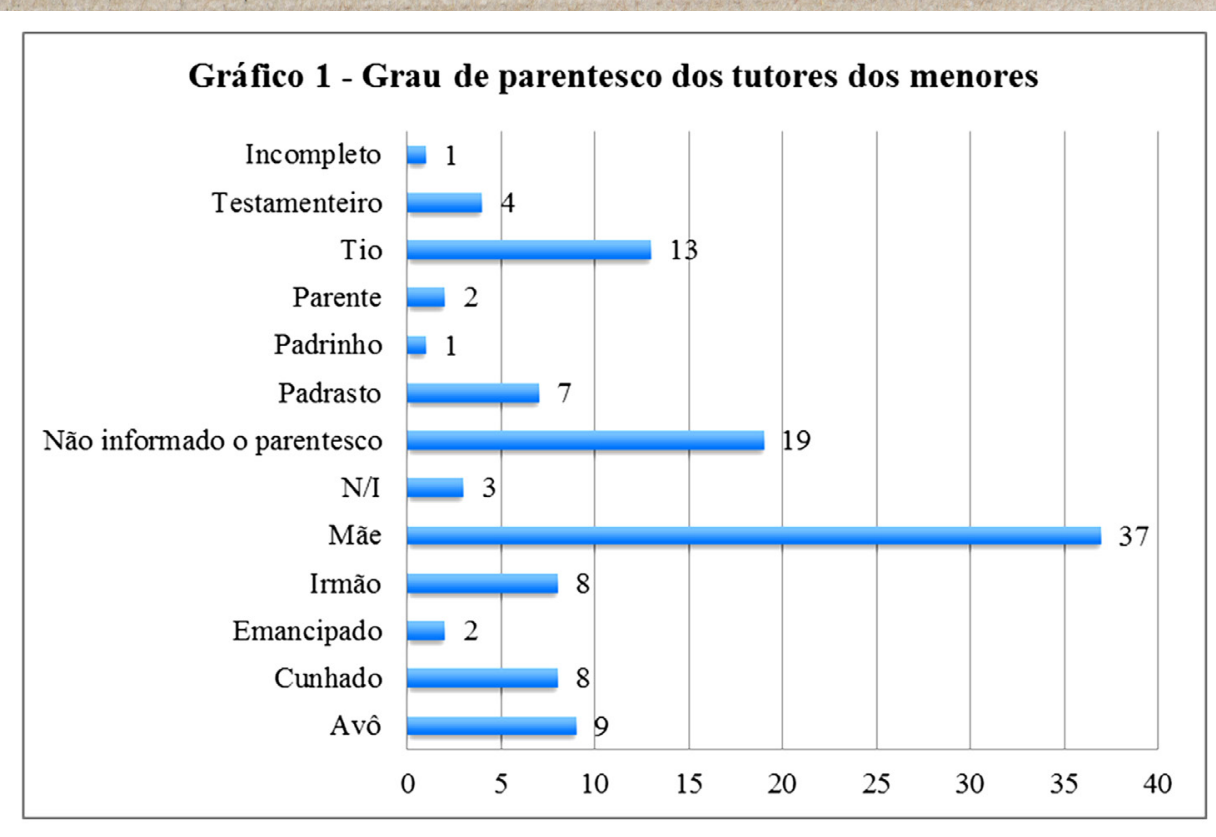

Fonte: Elaborado pela autora a partir de Inventários (1763-1808) disponíveis nas coleções Juízo de Órfãos e Ausentes, Juízo de Fora e Casa da Suplicação, pertencentes ao Arquivo Nacional do Rio de Janeiro.

22 delas foram indicadas em testamento pelos maridos, oito se identificaram como tutora e testamenteira - não sabemos qual a origem da tutoria -, cinco conseguiram a função por petição ao

10 "Do beneficio do Senatus consulto Velleano, introduzido em favor das mulheres que ficam por fiadoras de outrem. Por Direito é ordenado, havendo respeito à fraqueza do entender das mulheres, que não pudessem fiar, nem obrigar-se por outra pessoa alguma, e em caso que o fizessem, fossem relevadas da tal obrigação por um remédio chamado em Direito Velleano [...]" (ORDENAÇÕES, 1870, p. 858).

11 As Ordenações Filipinas estipulavam que pessoas próximas ao menor fossem indicadas para tutor do mesmo (ORDENAÇÕES, 1870 , p. 994 e seguintes).

12 Sobre a tutela de menores, ver também De Backer (2010) e Walker (2004). 
Conselho Ultramarino (CU) e em dois casos não foi possível identificar (N/I) como obtiveram a tutela (Tabela 1). Essas mulheres administraram, majoritariamente, heranças com mais de 1:000\$000 e menos de 100:000\$000 (Gráfico 2). Comparando-se com os outros tutores, temos que, a maioria daqueles que não a mãe, foram indicados para cuidar de patrimônios maiores de 500\$000 e menores de 10:0000\$000 (Gráfico 3).

Tabela 1 - Tutela (Mãe)

\begin{tabular}{|l|c|}
\hline Tipo & $\mathbf{N}$ \\
\hline Petição ao CU & 5 \\
\hline Indicação em testamento & 22 \\
\hline Tutora e testamenteira & 8 \\
\hline N/I & 2 \\
\hline Total & 37 \\
\hline
\end{tabular}

Fonte: Elaborado pela autora a partir de Inventários (1763-1808) disponíveis nas coleções Juízo de Órfãos e Ausentes, Juízo de Fora e Casa da Suplicação, pertencentes ao Arquivo Nacional do Rio de Janeiro,

Tabela 2-Número de mães viúvas tutoras dos filhos e número de escravos por faixa de tamanho de plantel

\begin{tabular}{|c|c|c|}
\hline \multirow{2}{*}{ FTP } & Viúvas & Escravos do casal \\
\cline { 2 - 3 } & $\mathrm{N}$ & $\mathbf{N}$ \\
\hline 0 & 0 & 18 \\
\hline $1-4$ & 5 & 81 \\
\hline $5-9$ & 12 & 87 \\
\hline $10-19$ & 6 & 272 \\
\hline $20-39$ & 11 & 312 \\
\hline $40 \mathrm{e}+$ & 2 & - \\
\hline N/I & 1 & 770 \\
\hline Total & 37 & \\
\hline
\end{tabular}

N/I: Não informado ou não identificado.

Fonte: Elaborado pela autora a partir de Inventários (1763-1808) disponíveis nas coleções Juízo de Órfãos e Ausentes, Juízo de Fora e Casa da Suplicação, pertencentes ao Arquivo Nacional do Rio de Janeiro.

Ao assumir a tutoria a mãe passava a administrar os plantẹ́is de escravos provenientes do antigo matrimônio, assim como todos os outros bens. Esses cativos pertenciam ao casal que, ao ser desfeito pela morte do marido, passavam para a autoridade da esposa sobrevivente até a decisão final do Juiz de Órfãos após a partilha. Ao examinarmos a Tabela 2, constatamos que a maioria das mulheres viúvas indicadas como tutoras de seus filhos provinham de casais que possuíam plantéis de escravos com mais de 5 e menos de 40 escravos. Pela mesma tabela vemos que houve uma concentração de escravos nas mãos de apenas duas viúvas. Se compararmos a Tabela 2 com os Cráficos 2 e 3 observamos que as mães tutoras administravam, proporcionalmente, patrimônios cujos montes-mores eram maiores do que aqueles em que outros parentes foram indicados para tutores, os quais se restringiam a faixas de riqueza menores de 10:000\$000 e, consequentemente, plantéis de cativos menores. 


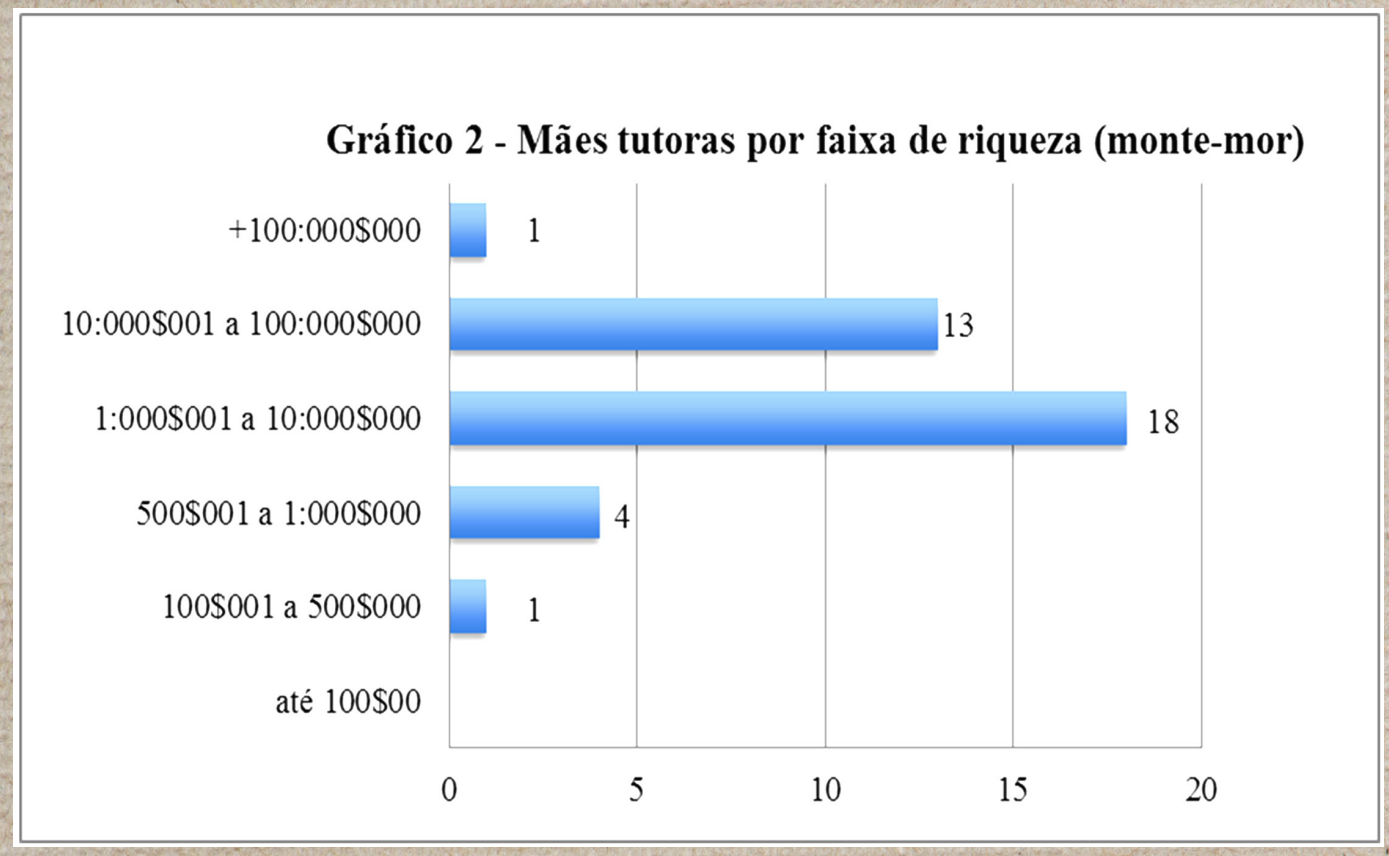

Fonte: Elaborado pela autora a partir de Inventários (1763-1808) disponíveis nas coleções Juízo de Órfãos e Ausentes, Juízo de Fora e Casa da Suplicação, pertencentes ao Arquivo Nacional do Rio de Janeiro.

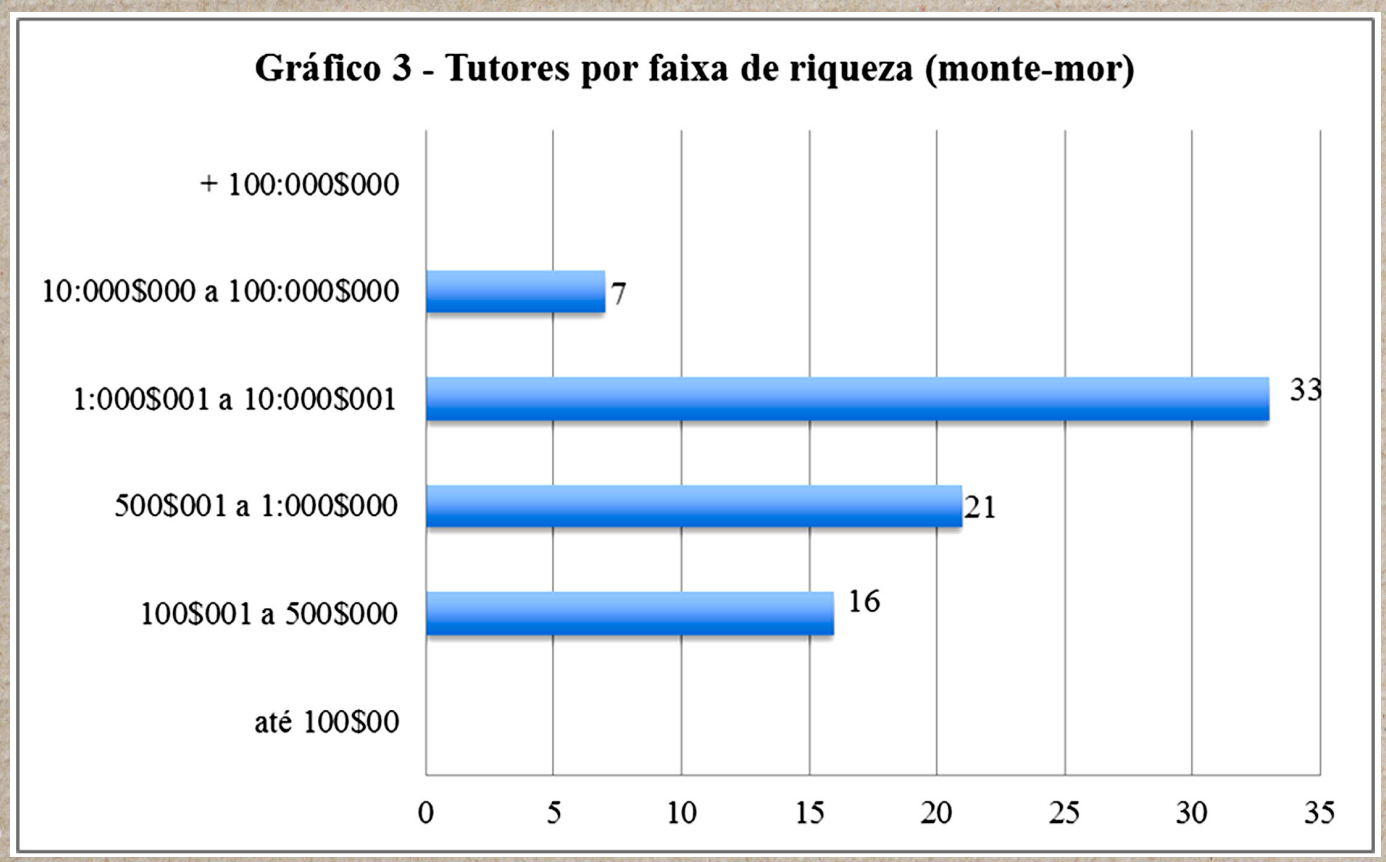

Fonte: Elaborado pela autora a partir de Inventários (1763-1808) disponíveis nas coleções Juízo de Órfãos e Ausentes, Juízo de Fora e Casa da Suplicação, pertencentes ao Arquivo Nacional do Rio de Janeiro:

A obtenção da tutoria estava condicionada ao cumprimento de algumas exigências legais, entre elas: não ter se casado novamente ${ }^{13}$, viver honestamente e ter capacidade para gerir os bens (ORDENAÇÕES, 1870, p. 998). Além de satisfazer essas condições, as mães deveriam apresen-

13 No Direito Romano, as mães podiam ser indicadas como tutoras, desde que não se casassem novamente (KUEFLER, 2007, p. 358). 
tar um instrumento de Justificação e prover uma fiança através de uma Provisão de Tutoria concedida pelo monarca ${ }^{14}$. Nos casos em que a viúva foi instituída em testamento pelo falecido este último podia isentá-la da fiança.

A Provisão deveria ser dirigida ao titular do trono - rei, rainha ou príncipe regente - e seria analisada pelos ministros do Desembargo do Paço. No Juízo de Órfãos da cidade do Rio de Janeiro a anuência real deveria ser requisitada quando as legítimas excedessem o valor de $60 \$ 000$. Entretanto, não encontramos esse documento em todos os inventários post-mortem apesar de ser uma condição para a obtenção da tutoria. Dona Joana Inácia da Luz [Ferreira], em 1796, a fim de obter a tutela da filha, seguiu a exigência processual:

Diz D. Joana Inacia da Luz Ferreira da cidade do Rio de Janeiro que no testamento com que faleceu seu marido Mateus de Souza Lopes, nomeou a Suplicante para Tutora de sua filha D. Laureana de idade de quatro anos; porém como no Juízo de Órfãos daquela cidade todas as vezes que as legítimas excedem de $60 \$ 000$, como a da Filha da mesma Suplicante, não se concede a administração delas ainda as Tutoras testamentárias sem Provisão de V. Mag., e pelo Documento junto tem a Suplicante justificação que se conserva no estado de Viúva honesta, e que tem toda a capacidade e bom discernimento para administrar a pessoa e bens de sua filha, que nenhuma outra pessoa educaria melhor que a Suplicante sua própria Mãe [...] (INVENTÁRIO, 1795a). ${ }^{15}$

No inventário do capitão José Ribeiro de Araújo, os próprios filhos asseveraram a boa capacidade de sua mãe tutora e testamenteira, Dona Joanà Teresa do Espírito Santo, para administrar sua legítima. Em 1802, Antônio Alves Ribeiro, 22 anos, e João Alves Ribeiro, 17 anos, garantiam ao Juiz de Órfãos que "pelos mesmos foi visto e examinado o presente Inventário com as Declarações feitas pela Inventariante as quais a provam e convém em tudo por conhecerem a boa administração que sua Mãe tem feito a seu benefício [...]" (INVENTÁRIO, 1798a).

Em outro processo, Dona Tereza Maria de Jesus ficou viúva de Antônio José Vieira Leitão, seu segundo marido, aos 24 de dezembro de 1803 (INVENTÁRIO, 1800) ${ }^{16}$. Era moradora na rua da Candelária Nova e estava muito doente quando remeteu a petição inicial ao Juízo de Órfãos. Do casamento ficaram os filhos Joaquim, de 18 meses, e Francisco, de dois meses. Em 26 de janeiro de 1804, José Pereira Duarte, avô materno, assinava o termo de tutor. Entretanto, os

$14 \mathrm{Na}$ França rural do século XVIII, a tutoria também podia ser entregue às mães, porém sua conduta deveria ser irrepreensível e ela deveria abdicar da tutela caso se casasse novamente. A tutela cessava quando os filhos completavam os 18 anos e as filhas 14 . Segundo Brigitte Maillard (1999, p. 217), esse privilégio baseava-se na ideia de que o amor que a mãe devotava ao filho a colocava em posição favorável perante outros candidatos ao cargo.

150 inventário de Mateus de Souza Lopes foi aberto em 11 de fevereiro de 1795 e existe um requerimento feito pela viúva ao Conselho Ultramarino em 1796 (REQUERIMENTO, 1796).

16 Quando casou com o inventariado, Dona Tereza Maria de Jesus já era viúva de Antônio de Ávila da Fonseca. Na listagem do Arquivo Nacional a data do processo está registrada como 1800 , porém o auto de inventário vem registrado como 26 de janeiro de 1804. Não existe folha de capa dos autos. (INVENTÁRIO, 1800). 
filhos de Dona Tereza Maria de Jesus viviam em companhia da mãe. Quando, em 1805, a viúva retomou o inventário que havia ficado parado, ela deu início ao processo para a tutoria dos órfãos no Juízo de Órfãos do Rio de Janeiro apresentando uma Justificação pela qual pedia para ser tutora para, assim, administrar o principal de suas legítimas, dando o pai como fiador:

[...] ficando a suplicante [Teresa Maria de Jesus] dos bens e inventariante deles [sic] como cabeça do seu casal para poder na sua divisão e dar partilha aos Herdeiros e como aos ditos Menores fiIhos da Suplicante por esquecimento de seu marido não nomeara tutor testamentário e a Suplicante os está alimentando e criando na sua companhia e tem capacidade Juízo e sizo e discrição para bem reger e administrar as pessoas e bens dos ditos seus filhos como tutora destes e serem os menores mais bem tratados e educados obrigando-se a pô-los no ensino muito melhor que outro qualquer pelo amor materno como se mostra do instrumento de Justificação junto (REQUERIMENTO, 1806, grifo da autora).

O que parece se destacar na petição acima é o fato de a inventariante ter ficado com os filhos e cuidar deles não só por sua competência para a tarefa, mas por seu amor materno. ${ }^{17}$ Todas as testemunhas arroladas pela justificante confirmam as argumentações da justificante para requerer a tutoria. Uma delas foi Alexandre José Bento, de trinta e três anos, que também era credor do casal, vivia de negócios e morava na travessa da Candelária. Pelo seu depoimento sabemos que ele conhecia a justificante e confirma suas alegações:

[...] disse que pelo pleno conhecimento que tem da ]ustificante, sabe pelo ver, que ela é viúva de dois Maridos, sendo o segundo Antônio José Vieira Leitão, que se conserva no Estado de Viuvez, com todo o crédito, honra e honestidade, que tem em sua companhia dois filhos menores a quem presta alimentos, e necessária educação e que é dotada de toda a capacidade e entendimento [...] (REQUERIMENTO, 1806).

Dona Teresa Maria relata, também, que o casal devia a credores do Porto e da Bahia, fazia negócios com comerciantes da cidade de Pernambuco, possuía oito moradas de casas térreas na rua do Senhor dos Passos e um sobrado na rua de São Joaquim. Também havia várias dívidas ativas e passivas que deveriam ser levadas ao monte (INVENTÁRIO, 1800, fl. 20v e seguintes), terras na freguesia de Inhomirim e quatro escravos. O monte-mor chegou a 10:439\$404-descontadas as dívidas e despesas, ficou para ser partilhado entre os herdeiros o valor de 4:950\$749.

Tal como fez Teresa Maria de Jesus em seu requerimento ao Conselho Ultramarino, apenas encontramos em três outros inventários referência ao amor da mãe como um fator que pudesse abonar as viúvas para serem tutoras dos filhos. Rosa Maria do Nascimento, Rosaura Maria da Conceição e Clara de Souza Paixão eram essas mães amorosas que pediam a tutela dos filhos.

17 Para úma discussão sobre a construção da figura materna ao longo da História, ver Badinter (1986) e Ariès (1975). 
Nesses casos o valor da herança variava entre $954 \$ 950$ e 8:572 $\$ 852$ e em apenas um deles foi o próprio marido falecido quem fez referência ao fato em seu testamento. João Caetano da Cunha, natural e batizado na freguesia de Il ha Graciosa, Bispado de Angra, em seu testamento indicava para tutores, em primeiro lugar, o capitão Antônio Luis Fernandes, que também era seu testamenteiro, e se esse não pudesse, sua esposa Rosa Maria do Nascimento:

[...] nomeia para tutora das suas mesmas filhas a referida sua companheira Rosa Maria do Nascimento por conhecer da sua capacidade e maternal amor zelará os bens das mesmas nossas filhas, se é que isso possa ter lugar em direito (INVENTÁRIO, 1806b).

Pelas palavras do testador, ele não tinha certeza se a tutoria da mãe seria possível, porém não foi preciso mais esclarecimentos no caso, pois Rosa Maria do Nascimento não foi nomeada tutora, o testamenteiro assumiu a tutela das herdeiras. Logo depois a filha mais nova se emancipou e a outra estava casada.

Francisco de Medeiros morreu em 28 de maio de 1808, deixando Rosaura Maria da Conceição viúva com duas filhas casadas, um filho maior de idade e Marcelino de 7 anos (INVENTÁRIO, 1808). O monte somava $954 \$ 950$ e entre os bens estavam um sítio em Perteninga (freguesia de Itaipu) com laranjeiras, uma morada de casa muito danificada, mais de 200 pés de café, um bananal, cana plantada, cerca de espinhos, alguns animais, uma roda de ralar mandioca e forno de cobre, ferramentas e cinco escravos.

A viúva não foi indicada pelo marido em testamento para ser tutora, mas em sua petição ao príncipe regente para pedir a tutoria do filho, ela argumentava que "n[ela] suplicante além de amor que lhe tem como mãe concorre toda a capacidade para o ser", (INVENTÁRIO, 1808). O príncipe regente, em Provisão Régia, assinada pelos ministros do Desembargo do Paço, concedeu à viúva a tutela em agosto de 1808 e, em dezembro do mesmo ano, Rosaura Maria da Conceição assinou o termo de tutora no Juízo de.órfãos. Sete anos depois, a mãe prestava contas de sua tutoria e pedia que seu fiador anterior fosse relaxado da fiança por estar velho e cansado, sendo indicado um novo. Pelo auto de perguntas feito pelo Juiz de Órfãos, a viúva esclareceu que o menor, Marcelino, continuava em sua companhia desde a morte do pai. Segundo ela, o filho estava sendo educado conforme suas possibilidades e aprendia os trabalhos da lavoura. A mãe também garantiu que os bens que foram adjudicados ao menor na partilha em 1809-um escravo, um relógio de algibeira, toda a prata do casal e o dinheiro que a inventariante deveria Ihe dar-continuavam em poder dela tutora.

A prestação de contas de Rosaura Maria da Conceição confirma que ela, como muitas outras viúvas, tinha a capacidade esperada para criar os filhos e administrar os bens. Clara de Souza 
Paixão ao tempo do falecido marido já se mostrava uma mulher capaz de conduzir a si eà sua filha, pois em seu testamento de 11 de setembro de 1797, Bernardo José Alves a instituíra tutora da filha e sua testamenteira. Pelo documento ficamos sabendo que Clara e Bernardo tiveram a filha quando ainda não eram casados, mas logo depois oficializaram a união, tornando a filha legítima. Por ele sabemos também que ele era um reinol e irmão da Ordem Terceira de São Francisco. O testamenteiro confiava em sua mulher, pois abonava Clara de qualquer fiança que lhe fosse imposta para a tutoria (INVENTÁRIO, 1797).

Também o capitão Manoel Francisco Peixoto, em seu testamento em 1800 , reputava à sua muIher competencia para a tutoria dos filhos do casal. Pelo documento ele relata que morava na rua da Lapa do Desterro e havia se casado com Dona Joana Rosa Matilde Trindade por carta de $\operatorname{arras}^{18}$. O marido tinha negócios em Lisboa e no Porto, de onde vinham as mercadorias para a loja de fazendas secas do casal.

Quando Manoel Francisco Peixoto morreu, em 23 de julho de 1805, o testamento foi aberto e, por ele, o falecido nomeava sua esposa como tutora dos filhos legítimos Maria Tereza de Jesus de 10 anos, Joaquina Teodora do Carmo de 9 anos, Francisca Rosa de Jesus com 6 anos, Justina Tereza do Amor Divino de 4 anos, Albino Francisco Peixoto com 18 meses e Manoel, póstumo, de 5 meses, bem como do filho natural Anacleto Francisco Peixoto. O testamenteiro justificava a escolha da esposa "pela muita capacidade que ela tem para a dita tutoria e a há por abonada em qualquer quantia que seja [...]" (INVENTÁRIO, 1806a). A tutoria foi confirmada pelo príncipe regente aos 9 de novembro de 1805 , entretanto, quatro anos depois ela já não aparece mais como tutora.

É provável que entre a data do termo de tutor assinado por Dona Joána Rosa e a divisão dos bens em abril de 1809 , a viúva tenha contraído segundas núpcias, pois ela foi destituída da tutoria nesse período e José Francisco Martins assinou novo termo de tutor. Em 1812, Dona Joana Rosa em vários documentos já aparecia como casada com Pedro Ursini (ou Ursim) Grimaldi. Foi o que vimos nos autos de sobrepartilha e em uma escritura de venda de duas moradas de casas térreas na rua do Sabão que fizeram Pedro Ursini Crimaldi e Dona Joana Rosa a José Antônio Vilela em 1812 (ESCRITURA DE VENDA, 1812, p. 7).

O risco de deixar os órfãos desamparados exigiu que as autoridades do período estivessem atentas às pessoas indicadas para a função. A função de tutor-quando a mãe não a assumia não podia ser ocupada por qualquer pessoa. Nossa documentação evidencia o cuidado que se

18 No casamento por carta de arras ou contrato de dote ou arras, os bens deveriam ser divididos de acordo com o que estava estipulado no contrato de arras, que havia sido acordado previamente - não havia comunicação de bens entre o casal. Sobre esse assunto, ver Silva (1984, p. 97-100). 
tinha em garantir que a tutela fosse desempenhada por parentes ou por alguém que garantisse a manutenção da legítima dos herdeiros. No inventário de Vasco Francisco Coutinho, o tio dos menores Vicente de 6 anos, Francisco de 3 e Florêncio de 1 ano foi indicado pelo escrivão Paulo Nogueira Lopes para tutor por ser casado e estabelecido (INVENTÁRIO, 1802, fl. 11). Em janeiro de 1808 o Juiz de Órfãos confirmou a indicação e o tio assinou termo de tutor.

Maria Teresa era viúva de Francisco Correia da Silva quando ela morreu, em 1795, deixando quatro filhos legítimos de seu falecido marido e mais três que teve no estado de viúva (INVENTÁRIO, 1795b) ${ }^{19}$. José da Silva assumiu o inventário e a tutoria dos menores, entretanto, o filho mais velho de Maria Teresa, Isidoro, de 15 anos, em uma petição ao Juiz de Órfãos contestava tanto a tutoria de José da Silva quanto a sua posição de inventariante. Nesta petição Isidoro explica porque o inventariante e tutor não poderia desempenhar as funções que lhe foram dadas:

[...] nomeando-se por tutor do suplicante e mais três órfãos que ficaram irmãos legítimos do suplicante a saber Genoveva, Leocadia e Delfino a um pardo por nome José da Silva Pereira sendo que este por modo nenhum pode ser tutor do suplicante e seus Irmãos por serem brancos e não só por este motivo mas por outros que por hora não declara por serem escandalosos aos próprios suplicantes também porque o mesmo pardo José da Silva não tem bens alguns com que assegurar a tutela [...] já por este respeito da Infer[ior] qualidade de tutor [o requerente Isidoro] se acha fora da casa na de um seu Tio José Cardoso de Moura por ter casado com uma Tia, irmã de sua mãe [...] sendo que o tutor sem reparar na diferença que vai do suplicante a ele o quer levar para sua companhia contra vontade própria assim o pratica com sua irmã Genoveva violentando-a a existir na Tijuca fora da companhia de seus parentes quando o seu destino é todo dirigido a vir para a casa de seu Tio João Comes de Gouveia casado e que vive com muita honra por isso e porque quer todo o direito e lei quando não há tutor testamentário dativo deve ser o parente mais próximo e mais grato a seus parentes órfãos por isso quer o Suplicante que VMce. se sirva remover a Tutela por mão e poder do dito ]oão Comes por ser casado com sua Tia irmã de sua Mãe e ser homem branco com estabelecimento de armazém e escravos o qual sendo necessário reforçará a segurança com fiador de bens de raiz [...] (INVENTÁRIO, 1795b, fls. 6 e 6V) ${ }^{20}$.

O escrivão, diante de tal situação, endereçou um ofício ao Juiz de Órfãos em 8 de julho de 1795 esclarecendo sobre o parentesco do inventariante e tutor com os menores e por que ele teria assumido o inventário. Nele consta

[...] que nenhum [parentesco] tem com os órfãos e que se fizera intruso inventariante para o fim de estar no sítio que pertence aos ditos órfãos, cujo sítio era pertencente ao Excelentíssimo Visconde de Asseca, e como o dito Inventariante não seja ou [sic] de boa conduta foi expulso do

19 Filhos legítimos: Isidoro, 15 anos; Delfino, 13 anos; Genoveva, 10 anos e Leocádia, 8 anos. Filhos naturais que teve no estado de viúva: Cândida, 6 anos; José, 1 ano e meio; e Maria, 9 meses.

20 Os grifos duplos são da autora e os grifos simples são do original. 
dito sítio pela administração [...] (INVENTÁRIO, 1795b, fl. 7V).

Quatro dias depois o curador de Órfãos, deu parecer favorável à petição de Isidoro, removendo a tutela "visto que ao suplicado [osé da Silva] faltam todas as qualidades para ser tutor e não" tem alguma; é pessoa muito pobre e deve ser removido da tutela [...]" (INVENTÁRIO, 1795b, fl. 8). Uma das qualidades a que o curador se refere, que faltava ao tutor, além de ser pobre, era o fato de que José da Silva era pardo e os tutelados brancos, como ressalta o menor Isidoro em sua petição, o que parecia ser muito grave para o rapaz. Ao insistir em destacar a inferior qualidade do tutor, o menor pretende salientar a diferença social entre ambas expressada na cor/ qualidade de cada um.

Nesse caso, o suplicado não preenchia nenhuma condição para assumir o cargo que pretendia. Através do uso de artifícios escusos, José da Silva tentou, por meio da tutela e da condução do inventário da falecida, voltar ao local em que viveu e de onde foi expulso. Ele tinha visto naquele processo uma oportunidade para garantir a administração do sítio dos menores na Tijuca que, apesar de não ser dos mais valiosos, tinha uma casa de palha, dois escravos, benfeitorias que incluíam mais de seiscentos pés de café e arvoredos.

Em outro processo, encontrar um tutor para a filha do alferes Maurício Pacheco Maciel exigiu certo cuidado (INVENTÁRIO, 1798b). O inventariado, que foi exposto na casa do médico José Pacheco de Vasconcelos e de Dona Rosa Maria Maciel na freguesia de Santo Antônio de Jacutinga, deixou Dona Bárbara de Araújo Barcelos viúva em fevereiro de 1798 carregando uma filha no ventre. Um ano e três meses depois da abertura do inventário, a viúva já estava casada com seu segundo marido, Manoel de Souza Dias, quando o escrivão dos órfãos procurava um tutor adequado para a menor. De acordo com o que relatou a autoridade do juízo, o avô era "desconcertado na capacidade" e o tio um perdulário que "tem estragado os seus teres" (INVENTÁRIO, $1798 \mathrm{~b}, \mathrm{fl} .9 \mathrm{v}$ ). A saída encontrada foi nomear o padrasto, que assinou termo de tutor aos 20 de julho de 1799.

Algumas vezes, as mães reclamavam dos tutores instituídos aos filhos e pediam a tutela para si. Ana Luíza dos Serafins argumentava, em um requerimento ao Conselho Ultramarino de 1770 , que o tio tutor de seu filho não estava cumprindo com sua função adequadamente. Ela disse ser

viúva do Tenente Coronel Francisco Xavier Barreiros, e moradora na cidade do Rio de Janeiro, que por seu falecimento Ihe ficou um filho de idade de cinco para seis anos chamado José Xavier Barreiros, a quem se nomèou por tutor um tio clérigo, que por the causar incômodo grave em tratar da boa educação do seu filho, estando em poder do dito tutor, e em separar-se a adminis- 
tração dos bens do casal, ficando sujeita a legítima respectiva à administração do tutor, pretende ser tutora do sobredito filho por concorrerem $n$ [a] suplicante todos os requisitos necessários para tratar da boa educação eadministração da legítima do dito seu filho [...] (REQUERIMENTO, 1770).

Através desse requerimento, a viúva demonstrava sua preocupação tanto com relação à formação quanto ao destino da herança do filho que corria perigo com a tutoria do tio. Por ele percebemos que as mães tutoras procuravam se mostrar como sendo as guardiãs mais adequadas para os filhos órfãos.

\section{Considerações finais}

Entendermos como as relações de poder moldaram as relações de gênero e como foram apropriadas pelas mulheres viúvas proprietárias no Brasil colonial, mas, sobretudo, como foram reordenadas a seu favor, permite-nos observar como essas mulheres criaram estratégias de sobrevivência, não apenas tangentes, mas perpendiculares, à sociedade tradicional na qual o senhor de escravo era uma das figuras de referência para esse período.

Os inventários post-mortem nos indicam que as mães tutoras e testamenteiras foram agentes importantes na economia da América portuguesa. Cabia a elas administrar patrimônios que incluíam terras, plantações e escravos. O predomínio de viúvas na gerência de monte-mores superiores a 1:000\$000, mas, sobretudo, entre as únicas responsáveis por patrimônios superiores a 100:000\$000, e plantéis de escravos numerosos nos apresentam mulheres que, segundo seus maridos, tinham capacidade tanto para cuidar de si quanto dos seus herdeiros.

Porém, elas deviam obedecer a normas específicas determinadas basicamente pelas Ordenações Filipinas e supervisionadas pelo Juízo de Órfãos. O Juízo de Órfãos e seus representantes regulavam e protegiam os herdeiros menores. Eles se preocupavam em garantir a manutenção das legítimas para não permitir que os órfãos ficassem desamparados quando chegasse o momento de resgatá-las.

Como administradoras de propriedades e de escravos, as mães tutoras penetravam em ambientes os mais diversos, ultrapassando frequentemente os limites entre as esferas do público e do privado, para garantir a sua manutenção e a dos filhos. Pelo que vimos, podemos sugerir que a átuação das viúvas ia muito além das alcovas ou da organização da cozinha, mas, sobre- 


\section{História Econômicag $\quad$ Dossiê
Demografia Históñóa}

tudo, podemos ver respingos de melado de cana nas saias das senhoras ou traços de farinha na tez bronzeada de muitas mulheres dividindo diariamente os espaços públicos e privados com os homens na sociedade colonial.

\section{Referências}

\section{Abreviações utilizadas:}

(AHU-R]): Arquivo Histórico Ultramarino, Rio de Janeiro

(AN): Arquivo Nacional

(cx.): caixa

(doc.): documento

(fl. e fls.): fólio e fólios

(gal.): galeria

(JOA AN/RJ): Juízo de Órfão e Ausentes, Arquivo Nacional, Rio de Janeiro

(mç.): maço

(proc.): processo

Fontes primárias consultadas:

ESCRITURA DE VENDA. Escritura de venda de duas moradas de casas que fazem Pedro Ursini Crimator [Grimaldi] e sua mulher Dona ]oana Rosa Matildes da Trindade, a ]osé Antônio Vilela, que vive de negócio - térreas, sitas na rua do Sabão, partindo de um lado com Dona Ana de tal e do outro com quem de direito for, livres de foro, havidas por arrematação na praça dos Ausentes. Banco de Dados da Estrutura Fundiária do Recôncavo da Cuanabara. AN, $1^{\circ}$. Ofício de Notas, 206, 27 de maio de 1812, p. 7. Disponível em: <http://mauricioabreu.com.br/escrituras/view.php?id=14084>. Acesso em:15 mar. 2017.

INVENTÁRIO. Joana Inacia da Luz e Mateus de Souza Lopes, proc. 9095, mç. 474, JOA AN/R], 1795 a.

INVENTÁRIO. Maria Teresa e José da Silva, proc. 9.147, mç. 475, gal. B, JOA AN/R], 1795b. 
INVENTÁRIO. Clara de Souza Paixão e Bernardo José Alves, 1797, proc. 8684, mç. 455, JOA AN/R], 1797.

INVENTÁRIO. Joana Tereza do Espírito Santo e José Ribeiro de Araújo, proc. 8.399, mç. 434, JOA AN/R], $1798 \mathrm{a}$.

INVENTÁRIO. Bárbara de Araújo Barcelos e Maurício Pacheco Maciel, proc. 8.503, mç. 440, JOA AN/R], $1798 \mathrm{~b}$.

INVENTÁRIO. Teresa Maria de Jesus e Antônio José Vieira Leitão, proc. 2.946, mç. 151, JOA AN/RJ, 1800.

INVENTÁRIO. Francisca Rosa Couveia e Vasco Francisco Coutinho, proc. 18, cx. 3.639, JOA AN/R], 1802.

INVENTÁRIO. Joana Rosa Matilde da Trindade e Manoel Francisco Peixoto, proc. 8.601, mç. 450, gal. A, JOA AN/R], 1806 .

INVENTÁRIO. Rosa Maria do Nascimento e João Caetano da Cunha, proc. 8.999, mç. 471, gal. B, JOA AN/ $\mathrm{RJ}, 1806 \mathrm{~b}$.

INVENTÁRIO. Rosaura Maria da Conceição e Francisco de Medeiros, proc. 11.038, mç. 702, JOA AN/R], 1808.

REQUERIMENTO. Requerimento de Ana Luiza dos Serafins, viúva do tenente-coronel Francisco Xavier Barreiros, ao rei [D. José], solicitando permissão para ser a tutora de seu filho menor José Xavier Barreiros. Rio de Janeiro, cx. 90, doc. 7.909, AHU-RJ, 18 de Julho de 1770.

REQUERIMENTO. Requerimento de Joana Inácia da Luz Ferreira, viúva de Mateus de Sousa Lopes, à rainha [D. Maria], solicitando provisão para ser tutora da sua filha de quatro anos, chamada Laureana. Rio de Janeiro, cx. 160, doc. 12.017, AHU-RJ, 16 de dezembro de 1796.

REQUERIMENTO. Requerimento de Teresa Maria de Jesus, por seu procurador Francisco Correia Fonseca, ao príncipe Regente [D. João], solicitando provisão para ser tutora e administradora dos bens e de seus filhos menores, conforme a vontade de seu falecido marido Antônio José.Vieira Leitão. Rio de Janeiro, cx. 234, doc. 15.984, AHU-RJ, 12 de fevereiro de 1806.

\section{Outros materiais bibliográficos:}

ABREU, Mauricio. Um quebra-cabeça (quase) resolvido: os engenhios da capitania do Rio de Janeiro-séculos XVI e XVII. In: FRIDMAN, F.; ABREU, Mauricio (Orgs.). Cidades Latino-Americanas: um debate sobre a formação de núcleos urbanos. Rio de Janeiro: Casa da Palavra, 2010. p. 63-89.

ALDEN, Dauril. Late Colonial Brazil. In: BETHELL, Leslie (Org.). The Cambridge History of Latin America. Cambridge: Cambridge University, 1984. p. 600-660. v. 2.

Royal Covernment in Colonial Brazil. Berkeley: University of California, 1968.

ARIĖS; Philippe. L'enfantet la viie familiale sous l'Ancien Régime. 2. ed. Paris: Seuil, 1975. 
ARRUDA, José Jobșon de A. O Brasil no comércio colonial. São Paulo: Ática, 1980.

BADINTER, Elisabeth. Um amor conquistado: o mito do amor materno. Rio de Janeiro: Nova Fronteira, 1986.

DE BACKER, Stephanie Fink. Widowhood in Early Modern Spain. Protectors, Proprietors, and Patrons. Leiden: Brill, 2010.

DIAS, Maria Odila L. Aspectos da ilustração no Brasil. Revista do Instituto Histórico e Geográfico Brasileiro, Rio de Janeiro, v. 278, p. 105-170, 1968.

FALCON, Francisco C. A época pombalina: política econômica e monarquia ilustrada. São Paulo: Ática, 1982.

FLORENTINO, Manolo C. Em costas negras: uma história do tráfico atlântico de escravos entre a África e o Rio de Janeiro (séculos XVIII e XIX). Rio de Janeiro: Arquivo Nacional, 1995.

FRACOSO, João. Homens de grossa aventura: acumulação e hierarquia na praça mercantil do Rio de Janeiro (1790-1830). Rio de Janeiro: Arquivo Nacional, 1992.

FRANCO, Stella Maris Scatena. Gênero em debate: problemas metodológicos e perspectivas historiográficas. In: VILLAÇA, Mariana; PRADO, Maria Ligia Coelho. História das Américas: fontes e abordagens historiográficas. São Paulo: Humanitas; Capes, 2015. p. 36-51.

KUEFLER, Mathew. The marriage revolution in late Antiquity: the Theodosian Code and later Roman marriage law. Journal of Family History, Reino Unido, v. 32, n. 4, p. 343-370, out. 2007.

LAMECO, Alberto Ribeiro. O Homem e o Brejo. Rio de Janeiro: IBCE, 2007.

LARA, Silvia Hunold. A legislação sobre escravos na América Portuguesa. 2000. Disponível em: <http://www. larramendi.es/i18n/catalogo imagenes/grupo.cmd?path=1000203>. Acesso em: 19 maio 2017.

LAVRADIO, Marquês de. Relatório do Marquês de Lavradio, Vice-rei do Rio de Janeiro, entregando o governo a Luiz de Vasconcellos e Souza que o sucedeu no vice-reinado. Revista Trimensal de Historia e Ceographia, Rio de Janeiro, v. 4, n. 16, p. 409-486, jan.1842.

LIVI-BACCI, Massimo. A Concise History of World Population. 2. ed. Oxford: Blackwell, 1997.

MAILLARD, Brigitte. Les veuves dans la société rurale au XVIIle siècle. Annales de Bretagne et des pays de l'Ouest, Rennes, v. 106, n. 1, p. 211-230, 1999.

MAXWELL, Kenneth. Conflicts and Conspiracies: Brazil and Portugal (1750-1808). London: Cambridge University, 1973.

McCAA, Robert. Calidad, clase, and marriage in colonial Mexico: the case of Parral, 1788-90. Hispanic American Historical Review, Durham, v. 64, n. 3, p. 477-501, 1984. 
ORDENAÇÕES FILIPINAS. Livro 4. Rio de Janeiro: Edição de Cândido Mendes de Almeida, 1870. Disponível em: <http://www1.ci.uc.pt/ihti/proj/filipinas/ordenacoes.htm>. Acesso em: 20 jan. 2015.

PAIVA, Eduardo França. Escravo e mestiço: do que estamos falando? In: PAIVA, Eduardo F.; CHAVES, Manuel F. Fernández; GARCÍA, Rafael M. Pérez (Orgs.). De que estamos falando? Antigos conceitos e modernos anacronismos - escravidão e mestiçagem. Rio de Janeiro: Caramond, 2016. p. 57-81.

PELLEGRIN, Nicole; WINN, Colette H. Veufs, veuves et veuvage dans la France d'Ancien Régime: actes du colloque de Poitiers, 11-12 juin, 1998. Paris: Honoré Champion, 2003.

PISCITELLI, Adriana. Re-criando a (categoria) mulher? In: ALGRANTI, Leila M. (Org.). A prática feminista e o conceito de gênero. Campinas: IFCH-Unicamp, 2002. p. 7-42.

RAMINELLI, Ronald. Nobrezas do Novo Mundo: Brasil e ultramar hispânico, séculos XVII e XVIII. Rio de Janeiro: FCV, 2015.

SAMPAIO, Antonio Carlos Jucá de. Na encruzilhada do Império: hierarquias sociais e conjunturas econômicas no Rio de Janeiro (1650-1750). Rio de Janeiro: Arquivo Nacional, 2003.

SCHAEFFER, Regina P. C. Espíndola; GEIGER, Pedro Pinchas. Nota sobre a evolução econômica da Baixada Fluminense. Anuário Geográfico do Estado do Rio de Janeiro de 1957, Rio de Janeiro, n. 4, p. 93-102, 1952.

SCOTT, Joan. Gênero uma categoria útil de análise histórica. Educação e Realidade, Porto Alegre, v. 16, n. 2, p. 5-22, jul./dez. 1990.

SILVA, Antonio de Moraes. Diccionario da lingua portugueza - recompilado dos vocabularios impressos ate agora, e nesta segunda edição novamente emendado e muito acrescentado. Lisboa: Typographia Lacerdina, 1789.

SILVA, Francisco Carlos Teixeira da. A morfologia da escassez: crises de subsistência e política econômica no Brasil Colônia (Salvador e Rio de Janeiro, 1690-1790). 1990. Tese (Doutorado em História) - Universidade Federal Fluminense, Niterói. 1990.

SILVA, Maria Beatriz Nizza da. Sistema de casamento no Brasil colonial. São Paulo: T. A. Queiroz, 1984.

WALKER, Katharina A. Seventeenth century Northern noble widows: a comparative study. 2004. Tese (PósDoutorado)-University of Huddersfield, Huddersfield. 2004. 